\section{Aportes a la} construcción de paz desde la comunicación y el tejido social: caso de los parceleros de Santa Paula (Córdoba)

\section{Paola Forero ${ }^{1}$}

paolaforos@gmail.com

Universidad Santo Tomás. Bogotá - Colombia

\section{Nadya Hernández ${ }^{2}$}

nadyahernandezb@gmail.com

Universidad Santo Tomás. Bogotá - Colombia

\section{Jairo Ordóñez ${ }^{3}$}

jairoordonez@usantotomas.edu.co

Universidad Santo Tomás. Bogotá - Colombia

Artículo recibido: 30/04/2015

Artículo aprobado: 11/06/2015

Para citar este artículo: Forero, P., Hernández, N. \& Ordoñez, J. (2015). Aportes a la construcción de paz desde la comunicación y el tejido social: caso de los parceleros de Santa Paula (Córdoba). Ciudad Paz-Ando, 8(1), 194-216

$1 \quad$ Psicóloga de la universidad Externado de Colombia. Estudiante de la maestría en Comunicación, Desarrollo y Cambio Social de la universidad Santo Tomás.

2 Comunicadora Social y Periodista de la universidad Autónoma de Occidente. Estudiante de la maestría en Comunicación, Desarrollo y Cambio Social de la universidad Santo Tomás. 3 Doctor en psicología de la universidad de Konstanz (Alemania). Comunicador Social de la universidad Central. Docente de la universidad Santo Tomás.

\section{Contributions to peace building through} communication and social fabric: The case of Santa Paula (Córdoba) Small

\section{Holders}

Aportes para a construção da paz desde a comunicação e 0 tecido social: caso dos parceleiros de Santa Paula (Córdoba)

DOI: http://dx.doi.org/10.14483/udistrital.jour cpaz.2015.1.a11

\section{Resumen}

El presente artículo aborda el caso de los parceleros de Santa Paula (en el departamento de Córdoba), como insumo para revisar los aportes que desde la comunicación y el tejido social sirven a la comprensión de la construcción de paz en el ámbito local. Se analizan, con especial interés, las relaciones sociales y las características del proceso comunicativo en este grupo, beneficiario de la política de restitución de tierras, que hace parte del proceso de reparación integral a las víctimas del conflicto armado colombiano.

Palabras clave: construcción de paz, tejido social, comunicación, restitución de tierras, Córdoba (Colombia). 


\section{Abstract}

This article presents the case of Santa Paula smallholders (in the department of Cordoba) as a supply to review the contributions that serve, form the communication and social fabric, to the understanding of the construction of peace at a local level. In addition, it analyses, with special interest, the social relationships and characteristics of the communication process in this group, which benefits from the land restitution policy that is part of the full reparation process given to the victims of the Colombian's armed conflict.

Keywords: peace building, social fabric, communication, land restitution policy, Córdoba (Colombia).

\section{Resumo}

Este estudo aborda o caso dos parceleiros de Santa Paula (no departamento de Córdoba) como ferramenta para analisar as contribuições que, desde a comunicação e o tecido social, servem na compreensão da construção da paz a nível local. São analisadas, com especial interesse, as relações sociais e as características do processo comunicativo neste grupo, beneficiário da política de restituição de terras, que faz parte do processo de reparação das vítimas do conflito armado colombiano.

Palavras-chave: construção da paz, tecido social, comunicação, restituição de terras, Córdoba (Colômbia).

\section{Introducción}

L a política de restitución de tierras que se viene implementando en Colombia desde el año 2012, cuenta a la fecha con 1.041 casos cuyos fallos restituyen 94.000 hectáreas en el país (Morales \& Segura, 2015). En el departamento de Córdoba se han dado 46 sentencias que devuelven las tierras a 340 familias, entregando 2.315 hectáreas (Unidad de restitución de tierras, 2015).

Estos avances son una forma de materializar los objetivos que se persiguen con los diálogos de paz de La Habana, pues los colectivos tienen la oportunidad de gozar de mejores condiciones de vida a las que antecedieron el conflicto (Ministerio del interior, 2011).

Esta coyuntura nos lleva a pensar en posibles escenarios post-conflicto, cuyo análisis debe aterrizarse en la geopolítica colombiana, particularmente en aquellas regiones que han sido fuertemente golpeadas por el accionar de los diferentes grupos armados ilegales, como es el caso de Córdoba.

Este Departamento ha sido escenario de los diferentes momentos de la historia de la violencia de los últimos 50 años (Observatorio de programa presidencial de Derechos Humanos y DIH, 2009). Más recientemente, se convierte en el espacio social en el que, tras décadas de dominio de frentes guerrilleros, surgen autodefensas como estrategia de expulsión contrainsurgente; grupos que en alianza con otras instituciones ilegales tomaron posesión de inmensas extensiones de tierra, generaron desplazamientos, abandonos y despojos. 
Este artículo es producto de la investigación realizada con los parceleros de la finca Santa Paula, ubicada en el corregimiento de Leticia, municipio de Montería. Ellos son beneficiarios de la política de restitución de tierras, y, en su tránsito a la reparación integral, se han convertido en caso emblemático, no solo en materia de ejecución de la política pública, sino también como proceso que despierta interés, al plantear la posibilidad de (re) construir vínculos y relaciones sociales que resultaron fracturadas a causa de la violencia (Ministerio del Interior, 2011). Este hecho resulta pertinente para analizar la forma en que se articulan e inciden las nociones de tejido social, comunicación y la construcción de paz en este caso.
En ese sentido, la revisión de este universo particular permite la comprensión de procesos similares, los cuales se irán dando cada vez con mayor frecuencia, en la medida en que se implemente la política de restitución de tierras como una forma de reparación a las víctimas del conflicto armado colombiano. Esto centra las preocupaciones, no solo en el aspecto jurídico y la formalización de propiedad frente a la tierra, sino en las relaciones que se dan en el plano social, y que exceden el abordaje material de la restitución, en tanto el retorno de un grupo no implica necesariamente la construcción de una comunidad o el restablecimiento del tejido social.

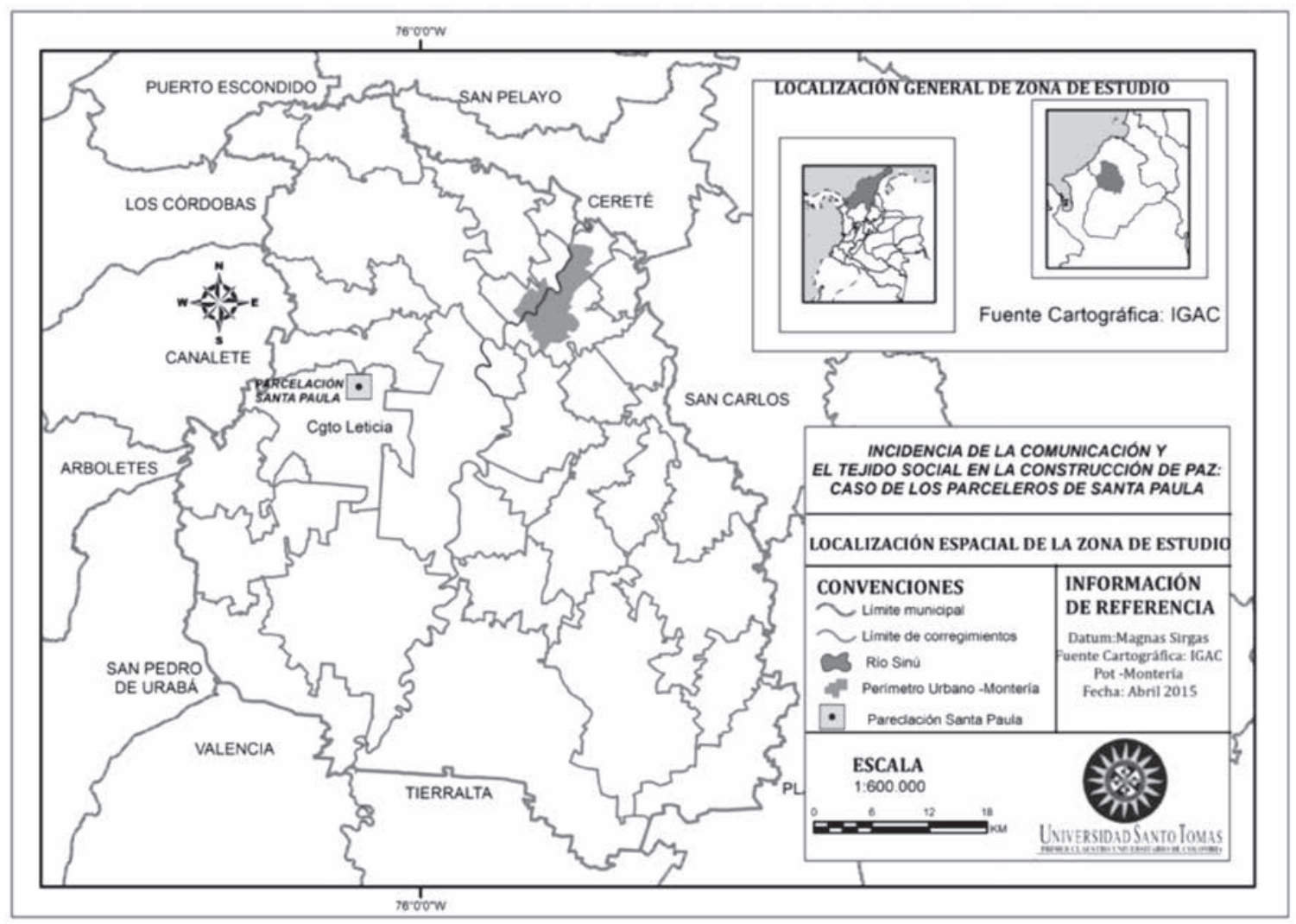

Figura 1. Localización de la Hacienda Santa Paula, departamento de Córdoba, Colombia 
En coherencia con el problema de investigación, el presente artículo ensambla tres unidades de análisis: construcción de paz, tejido social y comunicación. En un primer momento se desarrolla el contexto del caso, para luego abordar lo relativo a construcción de paz, sus implicaciones desde lo local, y su dimensión relacional. Posteriormente se describen y analizan las relaciones, redes e intereses que propician o dificultan la reconstrucción del tejido social. En un cuarto apartado, se integra la comunicación como proceso que complementa la matriz de análisis de la investigación, para finalmente dar cuenta del método y los hallazgos preliminares de este ejercicio académico. Por último, se desarrollan las conclusiones y la discusión de resultados.

\section{Contexto}

La hacienda Santa Paula es el escenario en el que se da el primer proceso de restitución de tierras en el departamento de Córdoba. Este predio se caracterizó por ser un latifundio (1.118 hectáreas) cuyos propietarios eran miembros activos de grupos armados ilegales (Círculo de periodistas de Bogotá, 2012). En la actualidad, se ha dado la restitución completa a 190 familias que han logrado el restablecimiento de sus derechos sobre las parcelas que un día les fueron donadas, y que nunca pudieron aprovechar a causa del dominio paramilitar en la región.

Las particularidades del caso están contenidas en la sentencia con expediente \#230013121001-2012-00001-00\#interno 024, del 13 de febrero de 2013, del Tribunal Superior, Distrito judicial de Antioquia, sala especializada en restitución de tierras, proferida por el juez Javier Enrique Castillo Cadena.
Para entender el hecho que les otorga derechos sobre la propiedad de la tierra a los beneficiarios de restitución de Santa Paula, se hace inminente entender la forma de adquisición de las parcelas y su posterior despojo a manos de las Autodefensas Campesinas de Córdoba y Urabá (ACCU).

A fines de 1990, y en la coyuntura del proceso de paz que se adelantaba con el Ejército Popular de Liberación (EPL), las ACCU o Tangueros, constituyen la Fundación por la Paz de Córdoba (FUNPAZCOR), liderada por Sor Teresa Gómez Álvarez, cuñada de Fidel y Carlos Castaño, quien asume la representación legal y la gerencia de esta organización; y que, en alianza con los sectores más influyentes de la sociedad y el poder económico de la región, crean un escenario de legitimidad sobre donaciones de predios que eran presentadas como aportes a dicho proceso. Esta "reforma agraria integral", consistía en entrega de tierras acompañada de asistencia técnica y financiación, entre las que se encontraban Las Tangas, Santa Paula, Arquía, Cedro Cocido, Las Chavarías, Doble Cero, Campo Alegre, Damasco, Tisló, Santa Mónica, Pasto Revuelto, Betulia, Jaragüay, La Pampa, Palma Sola, Roma, Las Campanas, Nueva Holanda, Micono, entre otras (El Tiempo.com, 2014).

Estas fincas fueron divididas en parcelas, que se asignaron a campesinos sin tierras de las zonas aledañas: jornaleros, miembros activos de las Autodefensas Unidas de Colombia y/o sus familias, desmovilizados del Ejército Popular de Liberación (EPL), y pobladores de barrios vulnerables de municipios como Montería, Tierralta y Valencia. Aunque en apariencia estas donaciones pretendían brindarle condiciones de restablecimien- 
to socioeconómico a los receptores, pronto se mostraron los verdaderos intereses que tenía la junta directiva de FUNPAZCOR; las donaciones fueron solo una fachada, ya que a los parceleros se les limitó la venta de los predios, hasta pasados 10 años de la entrega; y se les prohibió instalarse en sus propiedades o explotarlas de manera autónoma.

Sin embargo, con la muerte de Fidel Castaño en 1994, sus hermanos Carlos y Vicente quedaron al mando de las ACCU, cambiando algunas de las estrategias de la organización, lo que permitió que en algunos casos los parceleros, temporalmente usufructuaran los terrenos, y/o los habitaran. Pero en el año 1997, Vicente Castaño y Diego Fernando Murillo, alias "Don Berna", dan la orden de recuperar esas tierras y repartírselas entre sí, configurando el despojo del que serían víctimas los parceleros que dan origen al caso que aborda este documento.

Dicho despojo se ejerció de manera violenta, a través de amenazas y presión psicológica, frases como "si no vende usted, le compramos a la viuda", sembraron el terror entre quienes entregaron sus predios a precios irrisorios, o los abandonaron para evitar la represión de los armados, generando profundas heridas en la confianza, así como rupturas en las relaciones sociales y territoriales.

\section{Construcción de paz: una posibilidad desde lo cotidiano}

La transición del conflicto armado hacia la paz supone una profunda transformación de Colombia. Este proceso requiere esfuerzos que son posibles, pese a su complejidad, siendo la construcción de una paz estable y duradera, el reto global que en materia social tiene el país actualmente.
En esta línea, el Alto Comisionado para la Paz, Sergio Jaramillo, ha expresado:

Que las guerrillas dejen las armas es por supuesto una condición ineludible de la transición. Pero no es lo principal. Lo principal es lo que pasa después. Lo principal es entender la paz como una oportunidad, como una gran palanca de cambio para hacer lo que no hemos logrado hacer en cincuenta años de guerra. Se requiere la energía de la paz para poner en marcha la transformación de las condiciones que han mantenido vivo el conflicto. (2014, p.4)

Desde este punto de vista, la construcción de paz supone una participación amplia, fortalecida por una sociedad civil que reconoce su valor, y cuyos lazos sociales se han recuperado lo suficiente como para superar las lógicas del conflicto. Una paz, que requiere condiciones macro (la firma de los acuerdos entre las partes armadas), pero que solo es posible en los escenarios micro (la cotidianidad local).

En principio, es necesario plantear, desde el interés de este documento, que la construcción de paz no es una tarea que sucede a la firma de los acuerdos entre las partes en conflicto. Y que como lo ha propuesto Lederach:

la "construcción de la paz" es más que la reconstrucción posterior al acuerdo (...) la construcción de la paz se entiende como un concepto global que abarca, produce y sostiene toda la serie de procesos, planteamientos y etapas necesarias para transformar los conflictos en relaciones más pacíficas y sostenibles. (1998, pp. 47-48)

Nociones como la de paz territorial reconocen la trascendencia de los entornos locales y de las relaciones cotidianas como insumos nece- 
sarios para la transformación social, donde no hay actores sociales más relevantes que otros, sino que cada nivel de la sociedad tiene un rol:

Necesitamos que todos los sectores de la sociedad -campesinos, indígenas, afrodescendientes, empresarios, universidades, organizaciones sociales, miembros de la Iglesia- se sientan parte de un mismo proceso, que la paz es de ellos y con ellos, que todos pueden y deben aportar. (Jaramillo, 2014, p. 4)

Adicionalmente se destaca la importancia de reconocer a las víctimas como sujetos que contribuyen a la construcción de paz (Belloni, 2008), y no simplemente como objeto de las políticas de restitución de tierras y reparación.

Para hacer posible lo anterior, se requiere la transformación, no solo de las condiciones que dieron origen al conflicto, sino de las prácticas tradicionales donde la política pública se ejecuta de manera vertical; de modo que se escuchen las voces de los sectores base de la sociedad. Entonces, la construcción de paz adquiere sentido cuando se trasciende el enfoque top-down (de arriba hacia abajo), y se concentran los esfuerzos en estrategias bottom-up (de abajo hacia arriba).

Para comprender la noción de construcción de paz (peacebuilding), es necesario apelar a la forma en la que históricamente se ha abordado dicho concepto. En la Agenda para la Paz de Naciones Unidas (1992) se define Peacemaking como una acción que lleva a las partes hostiles a un acuerdo, obtenido por medios pacíficos, y Peace-keeping como una técnica para la prevención de conflictos -armados- y el mantenimiento de la paz, a través de la presencia de la ONU en el campo. Más tarde, en 1995 este mismo organismo incluiría en el Suplemento a la Agenda por la Paz el concepto Post-conflict Peace-building, definido como las medidas que se utilizan para evitar la recaída en el conflicto, así como para sanar las heridas que ha dejado el mismo.

Johan Galtung, trabajó desde la década de los 70 en la noción de construcción de paz como un proceso que trasciende a las élites y al Estado, centrándose en escenarios particulares, entendiéndola como "un emprendimiento político que tiene como objetivo crear paz sostenible enfrentando las causas estructurales o profundas de los conflictos violentos a partir de las capacidades locales para la gestión pacífica de los mismos" (Galtung, 1976, pp. 297-298). En esta línea denomina paz positiva a la ausencia de violencia estructural o indirecta, y paz negativa a la ausencia de violencia directa, pero con un gran componente de violencia estructural.

Pero esa construcción de paz no puede ser entendida en un nivel meramente abstracto, pues está ligada a múltiples perspectivas. Lederach (1998) propone un abordaje que comprende cuatro dimensiones: la personal, la relacional, la estructural y la cultural.

Para los propósitos pertinentes a este documento, señala que:

La dimensión relacional representa los cambios efectuados y deseados para la relación. Aquí tomamos en consideración las áreas de la interdependencia y la afectividad relacional, así como los aspectos interactivos, comunicativos y expresivos del conflicto. Descriptivamente, la transformación se refiere a cómo los modelos relacionales de la comunicación y la interacción se ven afectados por el conflicto (...) como receta, la transformación representa la intervención intencionada que reduce en lo posible los fallos en la comunicación y lleva 
al máximo el punto de entendimiento, y que saca a la superficie de manera explícita los objetivos, esperanzas y temores relacionales de las personas implicadas, en términos de afectividad e interdependencia. (Lederach, 1998, p. 112)

Considerando la importancia del contexto y la cultura, así como las particularidades locales, se evidencia que la construcción de paz se basa en las relaciones de las personas. Una afirmación que, pese a su sencillez, no carece de fuerza, pues como se advirtió en este apartado, además de abordar los niveles macro, es necesario observar, analizar y comprender la forma en que este concepto se entrecruza con lo relacional, la convivencia, la interacción y la comunicación.

\section{El tejido social que busca (re)construirse}

Pensar desde el ámbito de las relaciones sociales que se transforman por causa del conflicto armado requiere que se asuma una postura analítica lo suficientemente amplia e integradora que reconozca que no hay certezas incuestionables que den cuenta en su totalidad de la manera como se debería idealmente recomponer todo lo que la guerra quebrantó. Sin embargo, hace falta retomar modelos que sirvan de base para abstraer la forma como se entretejen, definen o configu- ran los vínculos de socialización, y que desde la comprensión de las ciencias sociales se ha denominado como tejido social. Conviene entonces en este punto revisar los elementos que incluyen abordajes para la definición de esta noción: Castro y Gachón (2001), como se citó en Chávez Plazas (2004, p. 178) plantean que el tejido social constituye un "entramado de relaciones cotidianas que implican relaciones de micro vínculos en un espacio local y social determinado" (2004, p. 178), lo cual supone la existencia de "relaciones dinámicas mutuas y de influencia recíproca entre los habitantes de una vereda, barrio, municipio o localidad, y que están cumpliendo una función de apoyo, soporte y movilización de los elementos fisiológicos y piscoafectivos a la persona" (2004, p. 178). En este sentido, el apoyo social se representa como un ámbito en el que a través de la cultura, costumbres y prácticas cotidianas se genera cohesión que hace posible perseguir algún fin determinado.

Romero (2006), como se citó en Romero, Arciniegas, y Jiménez (2006) asume el tejido social como un "conjunto de relaciones efectivas que determinan las formas particulares de ser, producir, interactuar y proyectarse en los ámbitos familiar, comunitario, laboral y ciudadano" (p. 19). Asimismo, plantea un modelo de análisis en el que puede comprenderse ese marco de relaciones. A continuación se muestra una figura en la que se recogen estos ámbitos relacionales. 


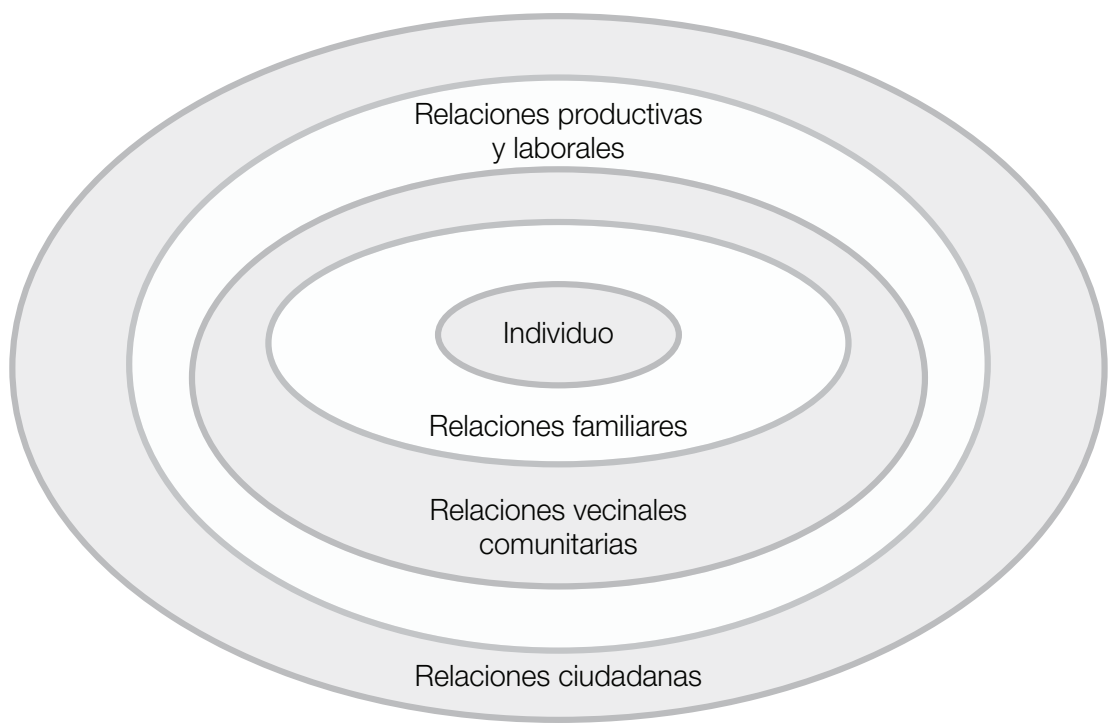

Figura 2. Representación gráfica sobre los ámbitos de relaciones que propone Romero (2006). Elaboración propia.

Los diferentes círculos representan entornos en los que se desenvuelve la vida de un individuo en interacción con otros: familiar, comunitario, laboral y ciudadano.

\section{El tejido social como urdimbre de redes}

Un abordaje que retoma la noción reticular, en analogía con los tejidos del orden microscópico que conforman órganos o estructuras más amplias y complejas, en el plano de las interacciones sociales, supone que las personas intercambian continuamente información y se retroalimentan en los diferentes escenarios sociales, tal como lo plantea Henao (1998):

Los vínculos sociales que permiten el desarrollo de la experiencia de vida, constituyen nudos, tramas, que han podido ser concebidas y distinguidas como redes de un vasto tejido social. Estas redes conforman, mediante una representación analítica, una especie de fronteras entre el individuo y la comunidad/socie- dad, entre su identidad y alteridad social, entre los sujetos que constituyen su conjunto social como un sistema aparentemente natural y el sistema social general. (p.10)

Lo cual implica que en grupos de individuos se establezcan diferentes tipos de relaciones que se enfocan en intereses o metas comunes. Henao (1998) propone que estas relaciones que están en el plano afectivo, económico, político o cultural, que se expresan en las interacciones cotidianas, y que a su vez "conforman una urdimbre de redes que han sido clasificadas en tres grandes grupos" (p.2):

- Redes de sociabilidad: entendidas desde la perspectiva de Joseph (1988): "como una urdimbre de relaciones selectivas y diferenciadas que hace que un individuo esté relacionado con un número limitado de personas" (p.133), integradas por las relaciones de vecindad, de amistad o de parentesco. 
- Redes de comunicación: relacionadas con la interacción cotidiana y sobre las cuales se profundizará el siguiente apartado.

- Redes de transacción: se relaciona con lo que Joseph (1988) reconoce como la movilización de recursos, y la negociación para la resolución de conflictos. A este tipo de red se apela cuando se busca o persigue un objetivo concreto, ayuda o favor para resolver un problema.

\section{Comunicación como columna vertebral de la vida en comunidad}

Para hacer posible la experiencia compartida, la vida en comunidad y el desarrollo colectivo, es necesario entenderse, intercambiar sentido, reconocer al otro, y poner de manifiesto opiniones e ideas; lo cual es posible a través de la comunicación, comprendida como práctica de interacción y de construcción de sentidos a partir de la cual se construye socialidad, es decir, nuestros modos de ser y estar juntos (Mata, 2009).

Las lógicas comunitarias son evidentemente comunicativas, pues es a través de la interacción, el diálogo, las percepciones, las subjetividades, los acuerdos y los disensos, que se consolidan las apuestas conjuntas.

Es importante destacar que el concepto de comunicación al que se hace referencia en este documento trasciende los modelos que privilegian el establecimiento de roles fijos entre el emisor (quien trasmiten la información) y el receptor (quien recibe dicha información), y se centra en una perspectiva en la cual la comunicación se entiende como proceso de interacción social democrática, que se basa sobre el intercambio de símbolos por los cuales los seres humanos comparten voluntariamente sus experiencias bajo condiciones de acceso libre e igualitario, diálogo y participación.

DERECHOS, NECESIDADES Y RECURSOS DE COMUNICACIÓN

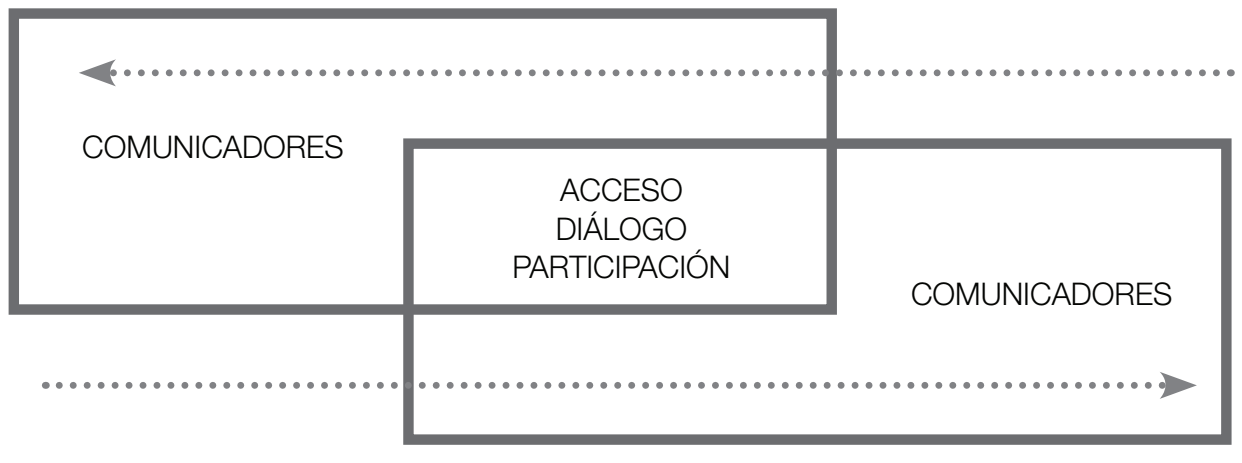

MÚLTIPLES FINALIDADES DE LA COMUNICACIÓN

Figura 3. Modelo de comunicación horizontal. Desarrollado por Beltrán, 1981, p.30 
Dado que este modelo se consideró para construir las categorías de análisis de esta investigación, se definen sus componentes:

- Acceso: es la precondición para la comunicación horizontal, ya que sin oportunidades similares para todas las personas de recibir mensajes, no puede haber interacción social democrática. Es un asunto cuantitativo, por lo cual se desestima para los intereses exploratorios.

- Diálogo: es el eje de la comunicación horizontal, y se comprende como lo contrario al monólogo. Además, es esta categoría la que convierte a los participantes del proceso de la comunicación en "comunicadores".

- Participación: es la igualdad de oportunidades para todas las personas de emitir mensajes (Beltrán, 1981).

En el mismo esquema se observa que el proceso comunicativo es un constante fluir entre comunicadores, mediado por los elementos mencionados en el párrafo anterior, y que dicha relación puede tener múltiples finalidades, toda vez que se da en un marco de derechos y necesidades, donde también es posible usar los recursos disponibles para alcanzar sus objetivos.

Por eso, cuando se afirma la necesidad de entender la comunicación como proceso, se propone al mismo tiempo recomponer el sentido narrativo de la historia a través de los procesos comunicacionales. Es decir, articular entre sí acontecimientos donde los actores sociales se construyen y constituyen simbólicamente, surgen como protagonistas, e im- pregnan de sentido el proceso histórico del que son partícipes (Uranga, 2009).

La revisión bibliográfica efectuada se centró en hallar desarrollos específicos sobre la comunicación en contextos comunitarios, acogiendo diferentes propuestas conceptuales que al respecto se han planteado: comunicación participativa, comunicación horizontal, edu-comunicación, etcétera; y a su vez, agrupándolas en una sola categoría, designada como comunicación para el cambio social (Alfaro, 2005; Gumucio, 2006; Servaes, 2008).

En su relación con el tejido social, se debe comprender que la comunicación tiene la capacidad de articular experiencias, otorgar sentido, establecer relaciones, generar encuentros, producir conocimiento, compartir saberes y armonizar prácticas sociales. Así como son constitutivas del tejido social las redes de sociabilidad y las redes de transacciones, lo son también las redes de comunicación

que suponen una reciprocidad profunda entre sus miembros, y permiten evidenciar la capacidad de los individuos o grupos de establecer acciones concretas con el fin de modificar su entorno social en situaciones que comprometen sus intereses, mediante códigos culturales y sistemas de comunicación y cohesión. (Joseph , 1988, p.134)

En el contexto en el que se da esta investigación, es imperativo reflexionar sobre el hecho de que el despojo del que fueron víctimas los parceleros de Santa Paula comprende lo material (la tierra), pero también representa rupturas en lo social, lo colectivo y lo simbólico, y la única manera de recuperar estos aspectos tiene que ver con el restablecimiento de lo relacional; es decir, la reconstrucción del tejido social, lo cual se posibilita a través de la comunicación. 


\section{Método}

La investigación desarrollada, de corte cualitativo, centra sus esfuerzos en el método de estudio de caso, por considerarlo el más apto para abordar la complejidad de los procesos y escenarios explorados. Es necesario mencionar que el estudio de caso no persigue una generalización estadística, tal como lo harían otros métodos y abordajes investigativos, sino el desarrollo de una teoría que puede ser transferida a otros casos con los que guarde o comparta características similares (Martínez, 2006).

El proceso inició con la revisión de fuentes secundarias para la construcción del contexto del caso. Posteriormente se aplicó una encuesta de caracterización entre los parceleros, con el objetivo de obtener insumos para el diseño metodológico, de modo que este fuera pertinente con las características de la población.

Otros elementos constitutivos de la metodología fueron las visitas exploratorias y de seguimiento a las parcelas, diseño y aplicación de instrumentos de recolección de información, sistematización y análisis de datos.

Si bien el proceso investigativo procuró ahondar en las relaciones sociales y la comunicación como procesos para la construcción de paz en Santa Paula, es una investigación que tiene un alcance exploratorio frente a un fenómeno de estudio novedoso, cambiante y dinámico; y, por tanto, no pretende cerrar la discusión en esta materia, sino abrir la puerta a escenarios de reflexión y análisis que redunden en acercamientos, colaboraciones e intervenciones más cercanas a las realidades y expectativas de los beneficiarios de la política de reparación integral, lo cual es un reto en materia metodológica y teórica.

En cuanto a los instrumentos, se imple- focales, mapas sociales, diarios de campo y entrevistas semiestructuradas.

En la visita exploratoria se aplicó la encuesta de caracterización mediante un recorrido para llegar a cada parcela. En total, fueron encuestadas 30 personas, entre hombres y mujeres, a las cuales se les indagó sobre aspectos como el lugar de procedencia, edades del núcleo familiar, máximo grado de escolaridad alcanzado, religión, etnia, ocupación y otros elementos relacionados con su participación en organizaciones sociales o comunitarias, valores con los que identifican al grupo de parceleros y reconocimiento de líderes.

Con los resultados a mano, se tomó la decisión de poner en marcha grupos focales sobre los temas de la investigación. Estos tenían dos objetivos: recolectar información concreta sobre las percepciones de los parceleros a través de ejercicios participativos de diálogo y puesta en común, y observar las características del proceso comunicativo en un marco de interacción narrativa. Tanto el número de asistentes, como la población participante fueron fluctuantes, pero se contó con un grupo base de cerca de 20 personas en cada ejercicio. Todas las sesiones se realizaron en Santa Paula.

En esta misma línea se implementaron mapas sociales que permitieron expresar las relaciones de atracción, desacuerdo, conflicto, jerarquía y dependencia que existen en cuatro ámbitos: relaciones familiares, relaciones vecinales y comunitarias, relaciones productivas, y relaciones ciudadanas, (Musito, Herrero, Cantera, \& Montenegro, 2004). Asimismo, sirvieron para obtener la red de actores y los vínculos que se establecen entre el grupo de parceleros.

Para contrastar y complementar la información obtenida se aplicaron entrevistas semiestructuradas; las preguntas realizadas 
giraron en torno a elementos que definen la noción de comunidad de los parceleros: sentido de pertenencia, interrelación grupal, participación, así como la descripción del concepto en sí mismo. Como último bloque, en la entrevista se indagó sobre paz y territorio, con fines de explorar la visión a futuro de los parceleros y su percepción sobre la construcción de paz.

Un instrumento transversal al desarrollo de la investigación fueron los diarios de campo, en los cuales se sistematizaron las observaciones que las investigadoras hicieron en los diferentes momentos del trabajo en materia de actitudes, comportamientos y reacciones que tenían los parceleros y ellas mismas durante ejecución de las actividades planteadas.

La información recolectada fue sistematizada a través del Software de Análisis de datos Cualitativos, Atlas ti 6.2, a partir del cual se realizó una lectura línea por línea. Este tratamiento de la información permitió el hallazgo de las diferentes subcategorías, vinculadas a las categorías y a las unidades de análisis de la investigación (Tabla 1).

\section{Hallazgos}

\section{Caracterización}

De los datos arrojados por la encuesta de caracterización se destacan los siguientes: no se evidencian elementos étnicos, de procedencia o religiosos, que aporten de manera contundente a la identidad del grupo de parceleros. El grueso de la población la componen hombres, entre los 48 y los 59 años, que en su mayoría han completado la primaria como grado máximo de escolaridad. En el territorio hay poca población infantil y juvenil. En cuanto a la vocación productiva, destacan la agricultura y la ganadería como formas de obtener el sustento económico de la familia.

\section{Tejido social}

\section{Relaciones Comunitarias}

En el plano de las relaciones comunitarias, los parceleros establecen vínculos a partir de valores comunes, formas comportamentales, de significados y de sentido que definen su identidad socio cultural:

ese sentido de pertenencia. La berraquera de uno haberse venido para acá. Porque para los que ya estamos, somos pocos los que estamos aquí, para los que ya estamos restituidos, somos pocos, entonces yo pienso que no es por la casa, ni por uno tener ganas, por ser berraco de venirse para acá. (Beatriz, 48 años)

Resalta la idea de la decisión y el carácter que tuvieron los parceleros para retornar, como una condición definitoria de su ser como colectivo; y en esta misma línea, la construcción de un referente histórico común que los identifica, y se vincula a la vivencia de los hechos de despojo y restitución:

De hecho yo pienso que todos hemos hecho parte de esa historia, porque desde el inicio desde nosotros estar acá, después nos quitan las parcelas, vivimos el desplazamiento, después la búsqueda de mirar nuevamente si otra vez nos devolvían nuestras tierras. (Beatriz, 48 años)

Esto llama la atención, en especial porque el despojo y la restitución están asociados al conflicto, y aparentemente el grupo parece no contar con elementos adicionales en su historia de vida común, de modo que los hechos violentos resultan como elemento, de cierta forma, unificador. 
Tabla 1. Mapa de categorías que guió el análisis de datos arrojados por los diferentes instrumentos

\begin{tabular}{|c|c|c|}
\hline Unidad de análisis & Categorias & Subcategorías \\
\hline \multirow{14}{*}{ Comunicación } & Acceso & Asunto cuantitativo \\
\hline & \multirow{6}{*}{ Diálogo } & Igualitarismo \\
\hline & & Cercanía \\
\hline & & Recurso de comunicación \\
\hline & & Influencia \\
\hline & & Dificultades/obstáculos en la comunicación \\
\hline & & Espacios de comunicación \\
\hline & \multirow{7}{*}{ Participación } & Estrategias de comunicación \\
\hline & & Movilización \\
\hline & & Metas similares \\
\hline & & Consenso \\
\hline & & Disenso \\
\hline & & Historias de vida \\
\hline & & Rituales \\
\hline \multirow{11}{*}{ Construcción de paz } & \multirow{11}{*}{$\begin{array}{l}\text { Dimensión relacional del } \\
\text { conflicto }\end{array}$} & Contextos en los que el conflicto se hace manifiesto \\
\hline & & Escalamiento \\
\hline & & Desescalada \\
\hline & & Necesidades básicas no atendidas \\
\hline & & Forma en que las personas se perciben a sí mismas \\
\hline & & Forma en que las personas se perciben unas a otras \\
\hline & & Forma en que las personas perciben el conflicto \\
\hline & & Proactividad \\
\hline & & Reactividad \\
\hline & & Paz positiva \\
\hline & & Paz negativa \\
\hline \multirow{19}{*}{ Tejido social } & \multirow{5}{*}{ Redes de sociabilidad } & Apoyo entre parceleros \\
\hline & & Relación entre parceleros \\
\hline & & Percepción de los parceleros sobre la asociatividad \\
\hline & & Individualismo \\
\hline & & Participación en actividades de esparcimiento \\
\hline & \multirow{2}{*}{ Redes de transacciones } & Relaciones vecinales \\
\hline & & Participación en proyectos productivos \\
\hline & \multirow{6}{*}{ Relaciones ciudadanas } & Acciones para la construcción de paz \\
\hline & & $\begin{array}{l}\text { Relaciones positivas de los parceleros con instituciones y } \\
\text { entidades }\end{array}$ \\
\hline & & $\begin{array}{l}\text { Relaciones negativas de los parceleros con instituciones y } \\
\text { entidades }\end{array}$ \\
\hline & & Visión a futuro \\
\hline & & Temor a la repetición de hechos de violencia \\
\hline & & Presencia de grupos armados \\
\hline & \multirow{2}{*}{ Liderazgo } & Gestión y apoyo de líderes \\
\hline & & Imagen de los líderes de Santa Paula \\
\hline & \multirow{4}{*}{ Sentido de comunidad } & Valores comunes \\
\hline & & Historia común de los parceleros \\
\hline & & Apropiación de las parcelas \\
\hline & & Relación de apropiación previa (al despojo) del territorio \\
\hline
\end{tabular}




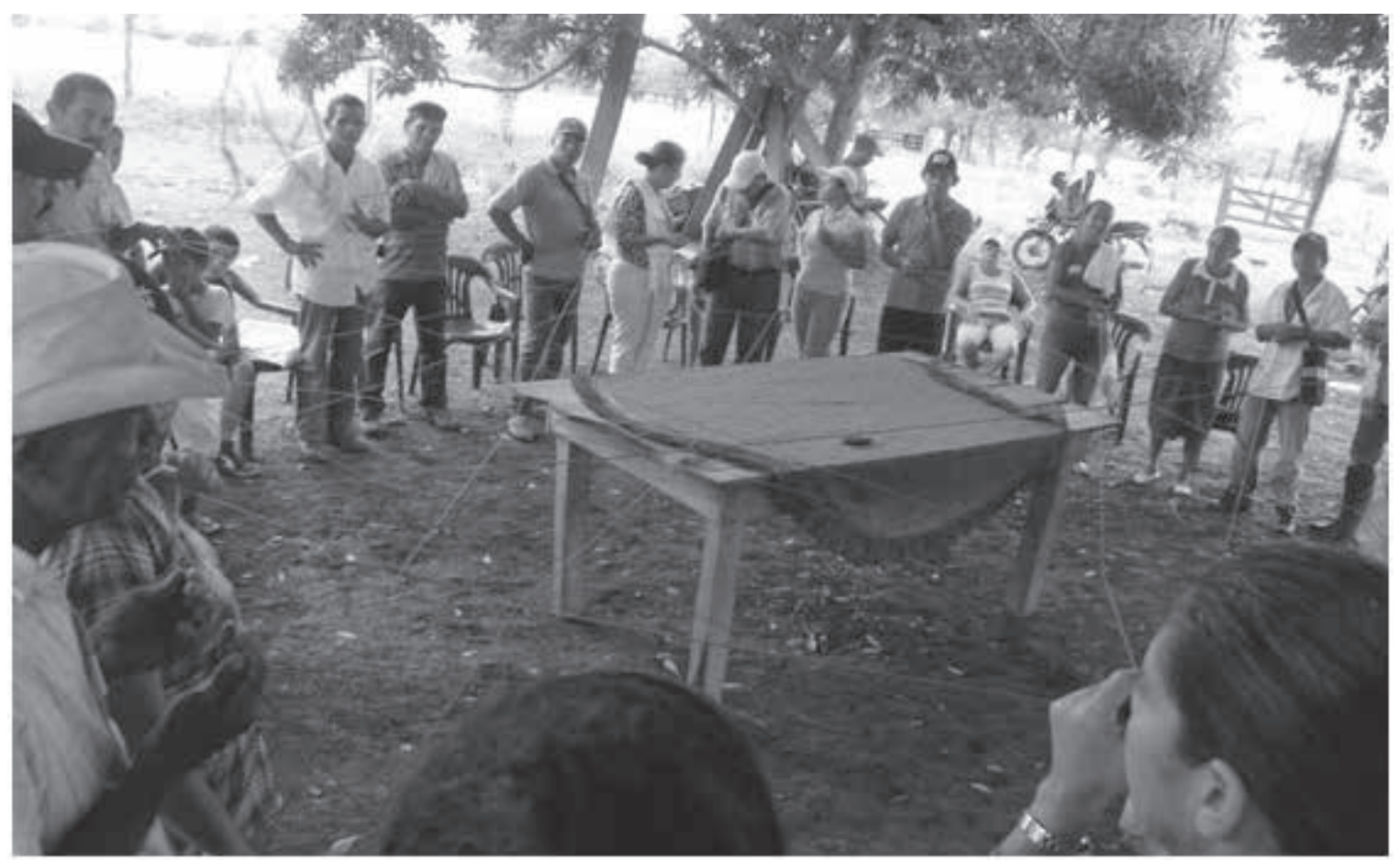

Parceleros en una dinámica donde se ponen en evidencia los lazos que se tejen a través de la cercanía

\section{Relaciones productivas}

Respecto a las relaciones productivas, se exploraron principalmente las actividades que permiten fomentar y movilizar recursos, tales como programas de generación de ingresos, y/o capacitaciones orientadas a actividades que les proveen recursos económicos. En este aspecto, se subraya la percepción positiva de los parceleros en torno a los programas y entidades que los respaldan: "El SENA sí, para qué decir que no si sí, porque el SENA ha estado pendiente, porque aunque los cursos no han terminado, son los que han estado más pendientes, yo hice el de piscicultura, y el de ganadería" (Joaquín, 57 años).

Igualmente, la posibilidad de ser productivos por sí mismos, propicia recursos de autogestión y de apropiación de la parcela:

ahorita nosotros tenemos desde recibir los alimentos, el ganado, la lechita, el queso, la mantequilla, por medio del queso uno consigue lo demás. Como uno hace el quesito fue y lo vendió o lo cambia por la yuca, lo cambia por la carne. (Julio, 63 años)

\section{Relaciones Ciudadanas}

En cuanto a las relaciones ciudadanas, se estudiaron especialmente el empoderamiento ciudadano y la formación en derechos y deberes. Se exploraron las acciones para la construcción de paz, asociadas a aportes y esfuerzos cívicos que conducen a la transformación de las relaciones entre los parceleros: "pues yo pienso que la paz empieza por casa, y vivir aquí nosotros en paz, que podamos de pronto tener buenas relaciones, que uno mantenga con el vecino, con el compañero, bien" (Joaquín, 57 años).

Otro hallazgo en esta materia tiene que ver con las relaciones que establecen como grupo con instituciones y entidades, y la conno- 
tación de las mismas: positivas o negativas. En el primer conjunto se incluyen aquellas que expresan confianza en organizaciones externas para el desarrollo de actividades, proyectos y programas que los benefician:

La policía. Ah no pues nos ha brindado confianza, se han relacionado bastante con nosotros, vienen constantemente, pues cuando han podido, nos brindan seguridad, y sí siempre han estado constantemente, se han relacionado bastante con nosotros, bueno digo conmigo, porque siempre que llegan a las casas preguntan y brindan confianza y a la vez también brindan protección. (Óscar, 40 años)

Consideramos que este es un hallazgo significativo, pues al ser las Fuerzas Armadas parte de los actores del conflicto, y en muchos casos victimarios de civiles, el grueso de la población desconfía de las figuras de autoridad. Un ejemplo de ello son los llamados "falsos positivos" (ejecuciones extrajudiciales), que sacaron a la luz las flagrantes y constantes violaciones de los derechos humanos por parte del Estado y la fuerza pública. Y sorprende más en la medida que se ha probado que fuerzas del Estado trabajaron conjuntamente con los Castaño, Don Berna, y otros paramilitares en la región de Córdoba.

En el segundo grupo, se encuentran aquellas en las que manifiestan inconvenientes, y se asocian principalmente a la negligencia o desatención a las necesidades manifiestas: "nos ofrecieron unos mercados, todavía no hemos visto el primero; las ayudas humanitarias, a unos cuantos se las dan a otros no" (Luis, 45 años).

El engaño y el incumplimiento aparecen de forma reiterativa como factores que debilitan la relación del grupo de parceleros con las entidades, lo que afecta su capacidad de interlocutar con la institucionalidad.

\section{Redes de sociabilidad}

El plano de las redes de sociabilidad, que como se mencionó en el apartado que define los conceptos claves de la investigación, permite entender hasta dónde se extiende el espacio de la comunidad en cuanto al apoyo entre parceleros; entendido como comportamientos cooperativos o de altruismo a través de la movilización de recursos y la negociación para la resolución de conflictos. Este nivel de relación hace alusión a las redes a las que se apelan cuando se busca o persigue un objetivo concreto; en Santa Paula la unión se manifiesta en hechos eventuales en los que han requerido del soporte de los demás:

La relación que tenemos nosotros es como familiar, porque nosotros nos tratamos aquí como hermanos, como si fuéramos de la misma familia. Un ejemplo aquí el señor Julio, si él un día no tiene plata y yo tengo, si él no tiene; y si él tiene y yo no tengo, también. Si yo un día por lo menos, no tengo para comprar comida 0 no traigo nada, la señora de él me llama, Luis venga a almorzar, mire. (Luis, 53 años)

La unión es un hallazgo en las relaciones de apoyo que aparece como recurso de afrontamiento a las adversidades que cotidianamente deben resistir los parceleros. Si bien esta resulta un recurso influyente, se plantea conforme se requiere o demanda, más no necesariamente como posibilidad de generar transformaciones o movilización en escenarios de participación. 


\section{Redes de transacciones}

Ahora bien, en cuanto a las redes de transacciones que configuran relaciones que persiguen objetivos concretos, la investigación tuvo como hallazgo que la cercanía física es clave para entender la manera como se relacionan los parceleros. En este sentido, las relaciones vecinales son un ejemplo para la movilización de recursos, negociación para la resolución de conflictos, ayuda o favor para resolver un problema, y que por tanto, se opta por "amigos y amigos de amigos con los cuales se puede hacer provisionalmente una alianza" (Joseph, 1988, p. 135).

De pronto tengo un vecino más cercano que es Pedro y de pronto con él sí ya más, de pronto ya con él le comento, y sí, nos apoyamos más acá. Porque estamos más cerca, por la cercanía, pero sí hay apoyo. Cualquier cosa yo lo llamo, vaya allá y me mira tal cosa y enseguida, y lo mismo cuando él necesita algo. Y aquí, por ejemplo, mire que ya va a venir el agua, saque el tanque, para que venga no lo agarre de sorpresa, y así, cualquier información que yo tenga, que sepa que es de ayuda para ellos. (María, 48 años)

\section{Redes de comunicación: lo narrativo como apuesta por el proceso comunicativo}

Como se describió en la sección sobre metodología, esta investigación apeló en procurar espacios de comunicación para que los parceleros se asumieran como protagonistas cuya voz, permanentemente obviada en su condición de víctimas, fuera escuchada y valorada, promoviendo el diálogo y la participación, recuperando la posibilidad de la interacción y, sobre todo, contando sus experiencias, deseos, visión del mundo y pro- yecciones. Todo ello a través de la puesta en común y el trabajo colaborativo.

Lo narrativo es esencial en el trabajo de campo en comunicación, pues como lo señala Martín-Barbero (2001):

Contar es tanto narrar historias como ser tenidos en cuenta por los otros. Lo que significa que para ser reconocidos necesitamos contar nuestro relato, pues no existe identidad sin narración ya que esta no solo es expresiva sino constitutiva de lo que somos. Tanto individual como colectivamente, pero especialmente en lo colectivo, muchas de las posibilidades de ser reconocidos, tenidos en cuenta, contar en las decisiones que nos afectan, dependen de la veracidad y la legitimidad de los relatos en que contamos la tensión entre lo que somos y lo que queremos ser. (p.10)

Este aspecto fue considerado de forma transversal en la aplicación de los instrumentos de recolección de información. La puesta en común haciendo uso de recursos de comunicación (imágenes, textos, oralidad) permitió identificar las particularidades del proceso comunicativo entre los parceleros de Santa Paula a través del análisis de las subcategorías diálogo y participación.

\section{Diálogo}

Recibir y emitir mensajes es un ejercicio que se posibilita y construye a través del igualitarismo, la cercanía, la influencia, y que se materializa a través de espacios y recursos de comunicación.

En el caso de los parceleros de Santa Paula, se evidenció que el diálogo es viable, pero aun no alcanza sus potencialidades por diversas razones; pese a que en las actividades grupales todos tenían la misma posibili- 
dad de acceder y participar, no todos sentían igual motivación, interés o daban por valiosos sus aportes. Esta situación derivaba en el cuestionamiento de si ello era así en otros escenarios, donde de manera individual algunos restringían su participación por considerar que lo que tenían por decir no fuese tomado como valioso.

Adicionalmente, la cercanía -como se indicó en el apartado sobre tejido social- está limitada a las relaciones vecinales. Durante los ejercicios prácticos, se encontró que algunas familias de parceleros no se conocen, esto también se debe a que no todos han regresado a sus tierras, y las dificultades en este proceso impactan las relaciones y en el proceso comunicativo que se gesta en las mismas. Sin proximidad (encuentro cara a cara), el diálogo entre iguales, en este contexto, es prácticamente imposible.

Pese a lo anterior, en algunos casos hay articulación y apoyo entre los que se consideran cercanos, bien sea por afinidad o por vecindad, y se evidencia un alto grado de influencia, que se traduce en el interés o acto de convencer al otro de adoptar determinada idea o comportamiento: "nosotros convivimos bien, porque por ejemplo, uno le recomienda uno al otro: mira por allá hay esto, o vamos a hacer esto, se comunica, nos comunicamos. Entonces ahí hay buenas relaciones" (Julio, 63 años).

En cuanto a los espacios de comunicación, estos podrían dividirse en formales y no formales. Los primeros, son constituidos con un objetivo puntual, es el caso de las reuniones internas o externas, asambleas, etc., los cuales son esporádicos e incluyen un grupo amplio. Según los hallazgos, todavía están por fortalecerse y comprenderse como lugares y momentos en los que los integrantes del grupo puedan revalorizarse y reposicionarse des de diálogo a nivel interno, y también con otros sectores de la sociedad. De momento son espacios transitorios, que van mejorando la cercanía y con ello la configuración del tejido social:

Las actividades a las que han venido y a nosotros nos ha tocado integrarnos, lo hemos hecho. Claro, nosotros nos unimos en eso, cuando nos toca. Yo le digo, yo no visito a nadie, pero si me toca una actividad nos encontramos, nos reímos, echamos cuento, participamos, nos ponemos de acuerdo, en fin. (María, 48 años)

Los segundos tienen más frecuencia y se valoran más que aquellos que están formalizados, por su distensión:

Sí, sí, hemos tenido reunión, a veces me vengo para acá, 0 donde Fabio, voy para allá a echarme una charladita, tranquilos, relajados, que no nos acordamos de los problemas. Porque todo el mundo tiene sus problemas, pero no nos acordamos de los problemas, sino de la tranquilidad, de lo que estamos hablando. (Joaquín, 57 años)

Dichos espacios son posibles gracias a la puesta en marcha de recursos de comunicación, los cuales se entienden como cualquier elemento energía/materia -cognoscitivo, afectivo o físico- utilizable para hacer posible el intercambio de símbolos entre los seres humanos. Son recursos de comunicación: los gestos, escritos, palabras, dibujos, etc, así como también material audiovisual, impresos, carteleras, entre otros.

Cabe resaltar que una vez los parceleros hacen uso de un recurso de comunicación, por ejemplo, un relato, privilegian una lectura casi ideal de la vida en común. Hay una búsqueda intensa de una historia de esperanza, emprendimiento y futuro. 


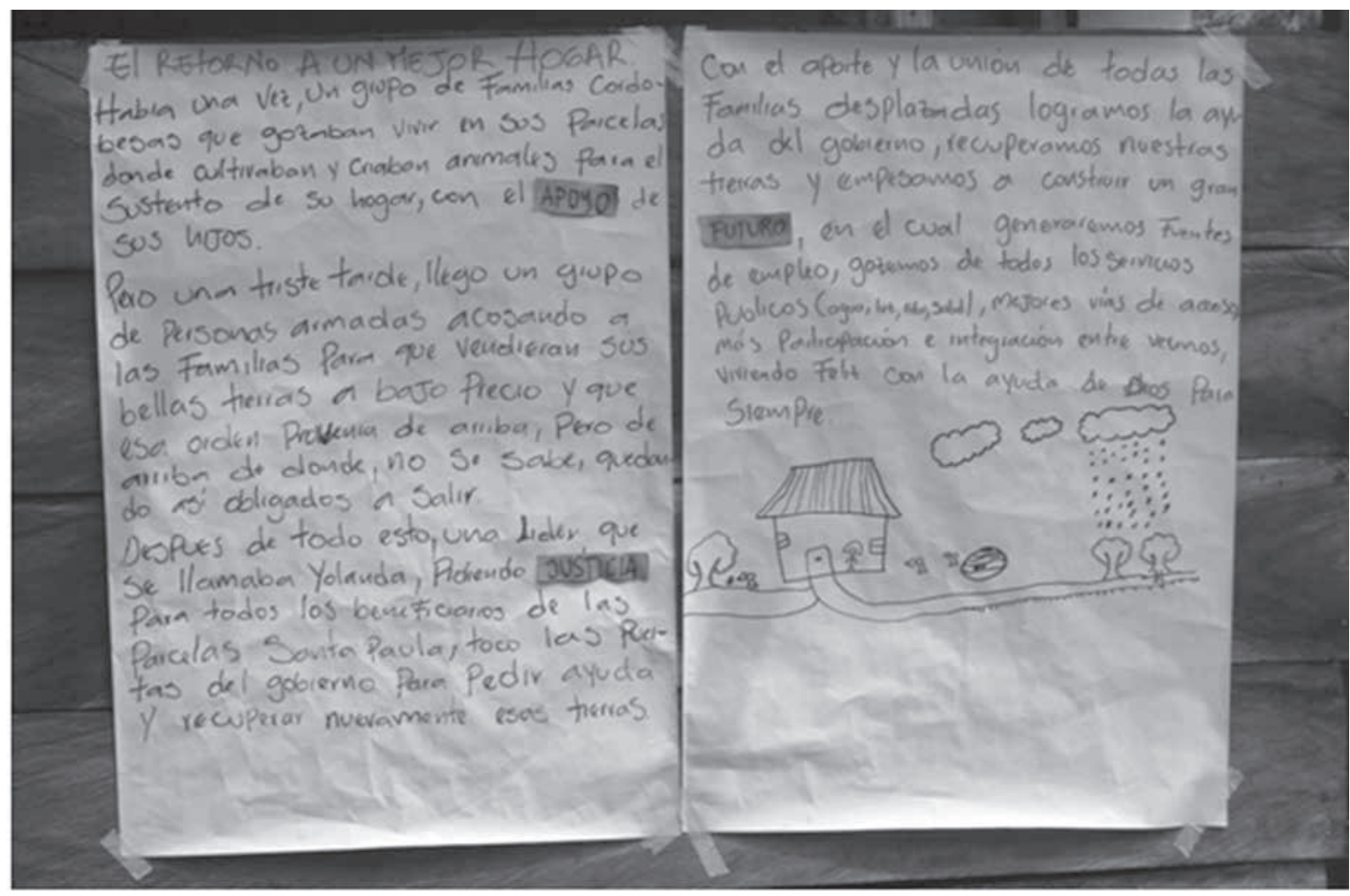

El relato de la foto surge de la pregunta ¿qué queremos los parceleros que se sepa de nosotros? en uno de los grupos focales.

\section{Participación}

Tomar parte en el ejercicio comunicativo supone un involucramiento activo por quienes se integran al mismo. Los hallazgos demuestran que los deseos individuales se suman al norte colectivo, en una meta similar que es transversal: la permanencia en el territorio. "Yo creo que nosotros no vinimos por un mes o dos meses, sino para estabilizarnos aquí, vamos a estar aquí, ¿cierto?" (Octavio, 55 años).

Gracias a esta perspectiva de estabilizar sus vidas en las parcelas, empiezan a darse muestras de movilización, es decir, de activación de procesos de cambio a través de gestiones, trámites y esfuerzos en pro del proyecto de sociedad que imaginan. Uno de sus mayores logros ha sido la adecuación de la vía de acceso:
Como cuando estábamos con el camino bien malo, íbamos a buscar al Alcalde, al Gobernador, y nos entrevistaban. Y esa es la comunidad de Santa Paula que está haciendo presión, porque ese camino tan malo, ni en la moto podía uno pasar. (Joaquín, 57 años)

Sin embargo, para que estos ejercicios se fortalezcan, es necesario consolidar los espacios de comunicación, los mecanismos de toma de decisiones, y la búsqueda de acuerdos, pues se perciben tensiones en estos aspectos: "Como a decir que uno los convida a hacer cualquier actividad, ellos impulsan, pero ya cuando están adentro yo no voy a perder el tiempo, mira que ya llevamos tiempo y quieren conseguir las cosas así, fácil" (Julio, 63 años). 
De otra parte, la ritualidad no es un aspecto fuerte en el grupo de parceleros, aunque hay un hito histórico relevante y que se concibe como ceremonia: la entrega de las parcelas, efectuada el 10 de abril de 2013; la cual contó con la presencia de altos funcionarios, como el Presidente Juan Manuel Santos, hecho éste que permanece en la memoria colectiva: "Yo pienso que la entrega. La misma entrega. El día que ya vino el Presidente y nos dijo aquí están los títulos, y nuevamente ustedes son los dueños de esta tierra (...) Fue algo como que muy significativo" (María, 45 años).

\section{Construyendo paz: la oportunidad de resarcir las heridas del conflicto}

Como se ha insistido a lo largo de este artículo, la construcción de paz debe estar conectada con las visiones locales en el ámbito relacional. Para comprender esta unidad de análisis, se exploraron los contextos en los que el conflicto se hace manifiesto, los niveles en los cuales progresa el mismo (escalamiento), las experiencias para transformar la cultura de guerra (desescalamiento), y las formas en que las personas se perciben a sí mismas unas a otras.

También se tomaron en cuenta las necesidades básicas no atendidas como asuntos fundamentales que producen insatisfacción en la población, así como la proactividad y la reactividad, en búsqueda de comprender la forma en que los parceleros asumen las situaciones que los afectan. Por último, se consideraron las nociones de paz positiva y paz negativa en un intento por identificar qué sentido se le da a la palabra paz y sus implicaciones en la vida en comunidad.

Se detectó que pese a que el conflicto es inherente a las relaciones humanas, y que su solución de manera violenta, los parceleros en general evitan confrontarse unos con otros, y las principales tensiones derivan de asuntos relacionales:

Si empezamos a tener esas discordias aquí dentro de poco nos van a soltar de madrinas, entonces aquí vamos a tener cada uno que sálvese quien pueda, pero para que el gobierno pueda respaldarnos por medio de proyectos, tiene que ser a través de... de la unidad y de grupo. Y si yo no me la llevo bien con el vecino, entonces sálvese quien pueda y a la hora de la verdad va a haber otro desplazamiento porque aquí la gente va a ser sálgase por donde pueda, entonces esto hay que regularlo. (Octavio, 55 años)

Este fragmento da cuenta también de otro aspecto importante y es la forma en que las personas se perciben unas a otras, y que tiene que ver con las construcciones del "otro", y en esta línea, la posibilidad de cimentar un "nosotros". En el bloque sobre tejido social se revisa con más detalle lo relativo al valor que tiene la unión del grupo de parceleros, pero en esta sección es importante destacar que ese "nosotros" es una lectura de la fuerza que tiene el colectivo, y cómo esto facilita su reconocimiento a nivel externo.

En materia de necesidades básicas no atendidas, se hallaron múltiples referencias a asuntos como la (falta de) vivienda, prestación de servicios públicos, acceso a salud y educación, entre otros: "Los servicios, la salud, todas esas cosas que debemos tener acá y que todavía no las tenemos. De lógica que si nosotros tenemos todo eso, vamos a estar mejor y vamos a vivir mejor" (María, 45 años).

Frente a las nociones sobre el concepto de paz, se encontraron componentes que hacen referencia a la paz positiva: 
Sí, porque me encuentro feliz. Me encuentro bien, con mi familia, con mis amigos, aunque no lo tengo todo, así como le había dicho. Pero sí, me encuentro en paz, bien, en ese sentido. Aunque no teniéndolo todo pero yo me encuentro en paz. Y tranquilo. Para mí eso es parte de paz. (Fabio, 53 años)

$Y$ de aquellos quienes interpelan por una comprensión de la paz negativa: "Para mí la paz es que no vuelva otra vez el conflicto armado, que no vuelvan las amenazas, y mucho menos muerte. Que no haya más ese temor" (Beatriz, 48 años).

Sin embargo, fueron más constantes las voces que relacionaban la noción de paz a la inexistencia de conflicto, así como a la ausencia de violencia directa, en términos de Galtung, una paz negativa. Esto como imaginario colectivo es muy inquietante frente a las perspectivas que el grupo de parceleros puede sustentar y construir en materia de paz, ya que se está obviando la violencia estructural - que es la más compleja-, y cuya superación garantiza la consolidación de la democracia y el ejercicio de una ciudadanía plena.

\section{Conclusiones}

Desde el abordaje de las redes de sociabilidad es importante resaltar que se cuenta con insumos como el apoyo y las relaciones vecinales, que se constituyen como aportes que promueven los intercambios entre los parceleros y que favorecen los sentimientos de unión, aspecto que permite mantener los lazos entre las personas que conforman la comunidad (Musito, Herrero, Cantera \& Montenegro, 2004). Es de resaltar que aunque exista una expectativa ideal de las relaciones comunitarias de no conflicto, o inexistencia de heterogeneidad, la realidad en las relaciones de intercambio plantean que "las personas por el hecho de compartir una comunidad, no son homogéneos entre sí y estas diferencias justamente proporcionan una riqueza para las relaciones sociales" (Musito, Herrero, Cantera \& Montenegro, 2004, p.47), por tanto no debe sorprender que en ocasiones los parceleros discrepen en las expectativas que tienen en las diferentes redes de sociabilidad.

En esa misma línea, habría que anotar que las relaciones comunitarias asociadas a la construcción de paz deben reconocer la existencia del conflicto como posibilidad de configurar procesos de desarrollo desde las expectativas propias del colectivo.

A propósito de los hallazgos en materia de necesidades básicas no atendidas, esto se establece como causa de la falta de empoderamiento, y de otras situaciones tales como: ausencia de cohesión, reactividad, y ausencia de capacidades instaladas; lo que puede ser efecto de la implementación de una política centrada en lo material, más que en un abordaje integral que propicie el fortalecimiento de los escenarios para la configuración autogestionada de tejido social.

Respecto a lo comunicativo, se evidencia que como proceso se encuentra aún en una etapa primaria, y que, para alcanzar sus potencialidades, será necesario implementar estrategias comunicativas que respondan a las necesidades de los parceleros como colectivo. Para ello, puede ser pertinente explorar alternativas como talleres formativos, cine foros, construcción de crónicas de radio, etc., y complementar estos esfuerzos mediante el fortalecimiento de espacios como asambleas, reuniones, planteamiento de proyectos colectivos, entre otros. Estas dos líneas permitirían ahondar en la comunicación como un elemento constitutivo, que articula y fortalece la vida grupal. Esto, a su vez, redundaría en 
la capacidad de ejercer una ciudadanía más activa, empoderada de sus derechos y conocedora de sus deberes, cuya interrelación con entes externos (Estado, agencias de cooperación, instituciones educativas, y otras) esté basada en la afirmación de las propias fortalezas, y la búsqueda por resolver problemáticas a todos los niveles, así como en la capacidad de visibilizarse de manera efectiva para sus propósitos como grupo humano.

Este elemento es materia prima para la construcción de la paz estable y duradera, ya que el ejercicio pleno de la ciudadanía fortalece el Estado de derecho, y la democracia, y con ello se crean las condiciones necesarias para asegurar la no repetición de hechos victimizantes.

En suma, la comunicación se evidencia como posibilidad de reconocer, sensibilizar y unir a través de la construcción de sentido colectivo. Como proceso humano, permite tejer intereses comunes, afectividades, visión a fu- turo, y a partir de todo ello cohesionar los elementos de la vida en comunidad, de manera horizontal, participativa e incluyente; todos los anteriores, elementos incontrovertibles de una sociedad en paz.

\section{Discusión}

La construcción de paz, el tejido social y la comunicación son elementos de una misma matriz que se retroalimenta y define mayores y mejores posibilidades de transformación del conflicto. La comunicación es el centro de las relaciones sociales sin las cuales no podría configurarse una urdimbre de redes para la construcción de paz.

Como una forma de enriquecer el triángulo del conflicto de Galtung (2003), se propone el esquema de la figura 4, que incorpora al original las nociones de tejido social y comunicación, como intrínsecamente ligadas a la empatía y la creatividad:

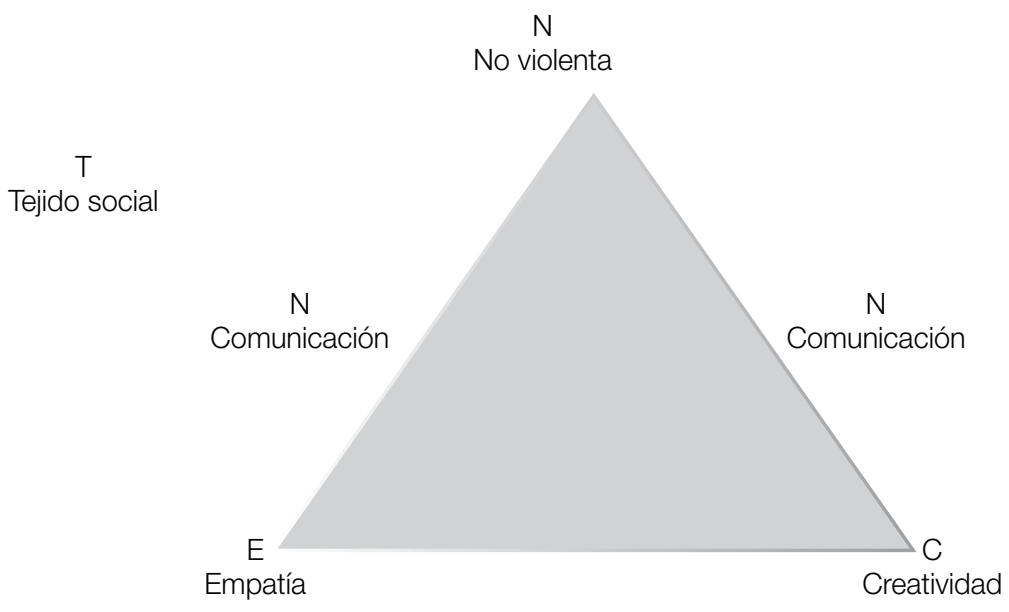

Figura 4. Triángulo de la No violencia que incorpora las nociones de tejido social y comunicación. 
Esta relación se evidencia en la forma en la que los grupos humanos son capaces de establecer intercambios a diferentes niveles, de acuerdo a sus propias necesidades, y, en ocasiones, con el objetivo de alcanzar metas comunes. Asimismo, estas relaciones están mediadas por las formas de ver y comprender el mundo y las prácticas culturales ligadas a lo político, económico, comunitario y social.

La manera en que el sujeto que ha sido víctima se comprende con relación al mundo, establece un marco que da forma a sus interacciones con otros iguales y así con las instituciones. Es necesario comprender que la restitución de tierras como parte de la reparación integral, solo cumplirá plenamente su labor cuando estas personas puedan reescribir su historia a partir de unas condiciones básicas de vida digna que restablecen sus derechos y les permiten transitar hacia un futuro que supera las condiciones de violencia que marcaron su pasado.

Si bien el Estado colombiano puede no contar con la capacidad institucional y la infraestructura económica para atender de manera completa todas las necesidades de la sociedad, sí debe contemplar en su política pública aspectos que permitan el fortalecimiento de las comunidades de base donde esta es implementada. De manera tal que exista una corresponsabilidad en la transformación de las desigualdades, la re- solución de conflictos y la ponderación de derechos y deberes, en búsqueda de un país con condiciones más dignas e incluyentes, tanto para las poblaciones rurales como para las urbanas.

Esto debe partir de la comprensión de que no por la formalización legal de la tenencia de la tierra se producen automáticamente lazos comunitarios y sociales que sirvan de insumo para la construcción de paz. En términos prácticos hay que sumar al componente jurídico los saberes de otras disciplinas para fortalecer el planteamiento y la implementación de las políticas públicas; y para ello es importante que el científico social se involucre en estos temas.

Para finalizar, es relevante hacer énfasis en que en el contexto nacional actual existe una urgencia por la investigación social aplicada, como compromiso de una academia que comprende su rol más allá de la producción científica, y que es capaz de contribuir activamente en la transformación histórica y la construcción de la paz. Esto es posible a través de abordajes interdisciplinarios y creativos, en coordinación con la comunidad para la búsqueda de cohesión y sana convivencia; así como para la confrontación de la teoría y la práctica; un ejercicio empírico tan necesario para aportar a la comprensión de fenómenos complejos, que requieren de reflexiones contrastadas en el terreno.

\section{Referencias bibliográficas}

- Alfaro, R. (2005). Derechos comunicativos para la afirmación ciudadana. Contratexto, (13), 46-72.

- Belloni, R. (2008). Civil society in war-to-democracy transitions . En A. Jarstad, \& T. Sisk (Edits.), From War to Demoracy: Dillemas of Peacebuiling (pp. 182-210). Cambridge: Cambridge University Press

- Beltrán, L. (1981). Adiós a Aristóteles: La comunicación horizontal. Comunicación y sociedad, (6), 5-35.

- Chávez Plazas, Y. A. (2004). Realidades y falacias de la reconstrucción del tejido social en población desplazada. Tabula rasa, (2), $169-187$.

- Circulo de periodistas de Bogotá. (26 de Septiembre de 2012). Colombia: demanda por finca de jefes paramilitares. Recuperado de http://goo. $\mathrm{gl} / 6 \mathrm{~N} 08 \mathrm{fm}$ 
- El Tiempo.com (18 de Marzo de 2014). La reforma agraria de los castaño fue una falacia: Fiscalia. Recuperado de http://goo.gl/cBIYxm

- Galtung, J. (1976). Three Approaches to Peace: Peacekeeping, Peacemaking, and Peacebuilding. En J. Galtung. Peace, War and Defense: Essays in Peace Research (pp. 282-304) (Vol. II). Copenhagen: Christian Ejlers.

- Galtung, J. (2003). Paz por medios pacíficos. Bilbao, España: Bekeaz.

- Gumucio, A. (2006). Seminario sin comunicación no hay desarrollo. Tiempo de Milagros: Tres retos de la comunicación para el cambio social. Lima.

- Henao, D. (1998). Comunicación y redes sociales. Bogotá, Colombia: UNAD.

- Jaramillo, S. (2014). Todo lo que debería saber sobre el proceso de paz: visión, realidades y avances en las conversaciones que adelanta el Gobierno Nacional en La Habana. En O. d. Paz, La Paz Territoria (pp.4-8). Bogotá, Colombia: Imprenta Nacional.

- Joseph, I. (1988). El transeunte y el espacio urbano. Buenos Aires, Argentina: Gedisa Editorial.

- Lederach, J. (1998). Construyendo la paz. Reconciliación sostenible en sociedades divididas. Bilbao, España: Bakeaz.

- Martín-Barbero, J. (2001). Políticas culturales de nación en tiempos de globalización. Revista Número, (31), 1-17.

- Martínez, P. C. (2006). El método de estudio de caso: estrategia metodológica de la investigación científica. Pensamiento \& Gestión, (20), 165193. Recuperado de http://goo.gl/W9UZ3X

- Mata, M. (2009). Comunicación comunitaria en pos de la palabra y la visibilidad social. En M. Mata, J. Huergo, W. Uranga, N. Ganduglia, G. Bergomás, J. Isella, y otros. Construyendo comunidades...Reflexiones actuales sobre comunicación comunitaria (pp. 21-34). Buenos Aires, Argentina: La Crujía.

- Ministerio del Interior. (20 de Diciembre de 2011). Decreto 4800. Artículo 167 y 168 . Bogotá.

- Ministerio del interior. (Junio de 2011). Ley de víctimas y restitución de tierras. Artículo 25 . Colombia.

- Morales, F., \& Segura, C. (25 de Abril de 2015). "Las metas se van a cumplir": director de Unidad de Restitución de Tierras. El Espectador. Recuperado de http://goo.gl/vR3NKM

- Musito, G., Herrero, J., Cantera, L., \& Montenegro, M. (2004). Introducción a la psicología comunitaria. Barcelona, España: UOC.

- Observatorio de programa presidencial de Derechos Humanos y DIH. (2009). Dinámica en el departamento de Córdoba 1967-2008. Bogotá, Colombia.

- Romero, Y., Arciniegas, L., \& Jiménez, J. (2006). Desplazamiento y reconstrucción de tejido social. Tendencia \& Retos, (11), 11-23.

- Servaes, J. (2008). Communication for development and social change. New Delhi: Sage.

- UN General Assembly/Security Council. (1992). An Agenda for Peace: Preventive, Diplomacy, Peacemaking and Peacekeeping . Nueva York.

- UN General Assembly/Security Council. (1995). Supplement to the Agenda for Peace: Position Paper of the Secretary General on the Occasion of the Fiftieth Anniversary of the United Nations. Nueva York.

- Unidad de restitución de tierras. (Enero de 2015). Informe final de gestión- Plan de Acción. Recuperado de https://goo.gl/2EirV4

- Uranga, W. (2009). Comunicación Comunitaria: Proceso Cultural, Social y Político. En M. Mata, J. Huergo, W. Uranga, N. Ganduglia, G. Bergomás, J. Isella, y otros, Construyendo comunidades... Reflexiones actuales sobre comunicación comunitaria (pp.177-186). Buenos Aires: La Crujía. 